\title{
Modeling Genetic and Environmental Influences in the Etiology of Conduct Disorder: A Study of 2,682 Adult Twin Pairs
}

\author{
Wendy S. Slutske, Andrew C. Heath, \\ Stephen H. Dinwiddie, Pamela A. F. Madden, \\ and Kathleen K. Bucholz \\ Washington University School of Medicine
}

\author{
Michael P. Dunne, Dixie J. Statham, \\ and Nicholas G. Martin \\ Queensland Institute of Medical Research
}

\begin{abstract}
The etiology of conduct disorder (CD) was examined retrospectively in a sample of 2,682 male, female, and unlike-sex adult twin pairs from the community-based Australian Twin Register Modelfitting analyses indicated a substantial genetic influence on risk for $C D$, accounting for $71 \%$ of the variance ( $95 \%$ confidence interval $[C I]=32-79 \%$ ). There was not a statistically significant effect of the shared environment in the best-fitting model of $\mathrm{CD}$, but a modest effect of the shared environment on the risk for $\mathrm{CD}$ could not be rejected (95\% $\mathrm{CI}=0-32 \%)$. The magnitude of genetic and environmental influences for CD liability did not vary significantly for boys and giris, and the specific genetic and environmental mechanisms important for the development of $C D$ appeared to be largely the same for both sexes. The fit of a multiple-threshold model raises the possibility that $\mathrm{CD}$ may not necessarily be a discrete entity but rather an extreme of the normal variation in conductdisordered behavior found in the general population.
\end{abstract}

Conduct disorder (CD) is one of the more prevalent childhood psychiatric disorders and one of the most common reasons that children are referred for psychiatric treatment (Kazdin, 1987; Robins, 1991). Children with CD, in addition to being more likely to suffer from other childhood psychiatric disorders (Anderson, Williams, McGee, \& Silva, 1987; Cohen et al., 1993), are much more likely than other children to suffer from alcohol and drug dependence, depression, anxiety disorders, and antisocial personality disorder (ASPD) as adults (Kazdin, 1987; Robins, 1978b; Robins \& Price, 1991; Rutter, 1995). In fact,

Wendy S. Slutske, Andrew C. Heath, Stephen H. Dinwiddie, Pamela A. F. Madden, and Kathleen K. Bucholz, Department of Psychiatry, Washington University School of Medicine; Michael P. Dunne, Dixie J. Statham, and Nicholas G. Martin, Epidemiology Unit, Queensland Institute of Medical Research, Brisbane, Australia.

Portions of this research were presented at the 25th Annual Meeting of the Behavior Genetics Association, Richmond, Virginia, May 1995, and at the Fourth World Congress on Psychiatric Genetics, Cardiff, Wales, August 1995.

This work was supported by National Institutes of Health Grants AA07535 and AA07728, by postdoctoral training Grants MH17104 and DA07261, and by a grant from the Australian National Health and Medical Research Council. John Constantino, Irving Gottesman, Matt McGue, and Lee Robins provided helpful comments on earlier versions of this article. We acknowledge the assistance of Randy Cates, Michael Hodge, Sue Mason, Theresa Pangan, John Pearson, Pam Saunders, Olivia Zheng, and the interviewers. We thank the twins from the Australian National Health and Medical Research Council Twin Register for their continuing cooperation.

Correspondence concerning this article should be addressed to Wendy S. Slutske, Department of Psychiarry, Washington University School of Medicine, Box 8134, 4940 Children's Place, St. Louis, Missouri 63110-1093. Electronic mail may be sent via Internet to wendy@ wupsych1.wuStL.edu. childhood CD may be one of the strongest predictors of psychopathology in adulthood.

Research and theory on the etiology of CD have emphasized the role of the family. In particular, a constellation of interrelated parental attributes such as ineffective parenting (Patterson, DeBaryshe, \& Ramsey, 1989), poor parental supervision and discipline (Frick et al., 1992; Loeber \& Dishion, 1983), parental conflict and divorce (Amato \& Keith, 1991; Emery, 1982), and parental separation (Fergusson, Horwood, \& Lynskey, 1994; Pearson, Ialongo, Hunter \& Kellam, 1994) have all been associated with childhood antisocial behaviors. These risk factors may reflect aspects of the child's social environment or, alternatively, because of their correlation with parental psychopathology, may reflect the child's genetic risk for antisocial behavior (Robins, 1978a; also see Lykken, 1995). Lahey, Hartdagen, et al. (1988) found evidence to suggest that the association between parental divorce and offspring $C D$ is due to parental ASPD, and Frick et al. (1992) found similar evidence for the role of parental ASPD in the association between poor parenting and offspring $\mathrm{CD}$. Thus, it is possible that the association between family variables and $C D$ may reflect a genetic rather than an environmental etiology (Lytton, 1990). Recent evidence from twin and adoption studies that bave shown that many of the family risk factors for $C D$ such as parenting behaviors and divorce are, in part, genetically inherited (McGue \& Lykken, 1992; Plomin, 1995 ) also supports the hypothesis that CD may be genetically inherited

Childhood antisocial behaviors have been shown to aggregate in families, as evidenced by significant sibling correlations (Rowe, Rodgers, \& Meseck-Bushey, 1992; Szatmari, Boyle, \& Offord, 1993) and associations between parental ASPD and offspring CD (Frick et al., 1992; Lahey, Piacentini, et al., 1988). The evidence from twin. adoption, and half-sibling studies concerning the relative magnitude of genetic versus shared family 
environmental influences in the etiology of $C D$ is mixed. There have been few twin or adoption studies of $C D$ per se. The most relevant existing behavioral genetic studies have more often been examinations of court-referred delinquency, self-reported delinquent behaviors, or mother-reported delinquent or externalizing behaviors. On the basis of these studies, most reviewers of the literature have concluded that the genetic influences on childhood antisocial behaviors are quite modest and that the shared family environment exerts a strong influence (e.g., Cloninger \& Gottesman, 1987; DiLalla \& Gottesman, 1989; Raine, 1993; Rutter et al., 1990), although some studies have found evidence of substantial genetic influences (Cadoret, Yates, Troughton, Woodworth, \& Stewart, 1995; Eaves et al., 1995; Grove et al., 1990; Rowe, 1983; Twito \& Stewart, 1982; Waldman, Pickens, \& Svikis, 1989). The results of the largest twin study of CD to date (of over 3,000 adult male Vietnam-era veteran twin pairs; Lyons et al., 1995) are consistent with conclusions from the reviews of the earlier studies. In the Vietnamera twin study, genetic infiuences accounted for less than $10 \%$ of the variance in retrospectively assessed self-reported childhood $\mathrm{CD}$ symptoms, and shared family environment accounted for about $30 \%$ of the variance. The remaining variance in childhood CD symptoms (about $60 \%$ ) was explained by individualspecific environmental factors.

It is unclear to what extent methodological differences, such as differences in sample ascertainment (e.g., court-referred, clinic-referred, or community volunteers), the age distribution of the sample (e.g., preadolescent, adolescent, adult), the methods of assessment (e.g., questionnaire, interview, official record), or the source of information (e.g., self-report, parentreport) may explain differences in results of behavioral genetic studies of childhood antisocial behaviors. In addition, most recent twin studies of childhood antisocial behaviors (e.g., Edelbrock, Rende, Plomin, \& Thompson, 1995; Grove et al., 1990; Lyons, et al., 1995; Rowe, 1983) have used continuous measures such as behavior or symptom counts rather than $C D$ diagnoses. The inheritance of antisocial or delinquent symptoms may or may not be the same as the inheritance of the more extreme pattern of behavior that corresponds to diagnosable $\mathrm{CD}$. In other words, whether $C D$ is a discrete entity or an extreme of normally occurring behavior remains to be determined (Hinshaw, 1994; Hinshaw, Lahey, \& Hart, 1993). Behavioral genetic studies are particularly valuable in addressing such questions. For example, Nichols (1984) established that the inheritance of certain forms of mental retardation differs from the inheritance of general intelligence by examining the measured IQ of siblings of mildly versus severely retarded children (see Plomin, DeFries, \& McClearn, 1990). Similar methods can be used to determine the extent to which continuous measures of antisocial and delinquent behaviors from the general population share the same risk factors as CD.

One of the most consistent, but as yet unexplained, findings for $C D$ is the marked sex difference in the rate of the disorder. This prevalence difference may reflect sex differences in the etiology of $\mathrm{CD}$. There is evidence to suggest that the risk factors for $C D$ may differ in boys and girls, but aiso that there are many commonalities. Cloninger, Christiansen, Reich, and Gottesman (1978) illustrated how family data can be used to examine sex differences in the causes of psychiatric disorders by comparing the similarity of male and female same-sex and unlike-sex (i.e. male-male, female-female, male-female) pairs of relatives. They found that the familial causes of adult ASPD are largely overlapping in men and women, but that women require more familial risk factors before they are affected. Few behavioral genetic studies have been capable of examining sex differences in the etiology of childhood antisocial behaviors, either because data on female probands (e.g., Lyons et al., 1995; Twito \& Stewart, 1982) or unlike-sex sibling or twin pairs (e.g., Edelbrock et al., 1995; Rowe, 1983; Stevenson \& Graham, 1988) were not available. Some studies suggest that genetic influences may account for a larger proportion of the variation in childhood antisocial behaviors in boys than in girls (Silberg et al., 1994; Stevenson \& Graham, 1988; van den Oord, Boomsma, \& Verhulst, 1994), although this is not universally found (Rowe, 1983) and is inconsistent with the literature on childhood antisocial behavior in boys (including the Vietnam-era twin study) that suggests very modest genetic influences. In sum, the general question of sex differences in the etiology of $\mathrm{CD}$ remains unresolved because data on the development of $C D$ in girls are scant (Goodman \& Kohlsdorf, 1994; Rutter \& Giller, 1983; Zoccolillo, 1993).

The present study is an analysis of twin similarity for retrospectively assessed childhood $C D$ in a sample of 2,682 male, female, and unlike-sex adult Australian twin pairs. We examined the following three main issues in the etiology of CD: (a) the relative role of genes, shared family environment, and nonshared individual-specific environment in the development of $\mathrm{CD}$; (b) the extent to which the etiology of $\mathrm{CD}$ is similar in boys and girls; and (c) whether normal-range conduct problems or subclinical manifestations of $\mathrm{CD}$ lie on the same liability dimension and share the same risk factors as diagnosable $\mathrm{CD}$.

\section{Method}

\section{Participants}

The participants were from the Australian National Health and Medical Research Council Twin Register (ATR), a volunteer twin panel recruited through the media, schools, and a variety of other sources (Jardine \& Martin, 1984). Three major health and behavior-related surveys have been conducted to date with the ATR sample: a mailed questionnaire survey in 1980-1981 ( $N=8,183$ individuals; $69 \%$ overall individual response rate for questionnaire; Jardine \& Martin, 1984), a follow-up mailed questionnaire survey in 1988-1989 of all complete twin pairs from the 1980-1981 survey ( $N=6,327$ individuals; $83 \%$ overall individual response rate for questionnaire; Heath, Cloninger, \& Martin, 1994; Heath \& Martin, 1994), and a telephone interview survey conducted in 1992-1993 ( $N=5,889$ individuals; $86 \%$ overall individual response rate for interview; Heath, Bucholz, et al, 1994). Data obtained from the telephone interview survey and the 1988-1989 questionnaire survey were analyzed for the present study.

Telephone interviews were attempted with any twin pairs in which at least one twin responded to the 1988-1989 mailed questionnaire survey ( $N=6,664$ individuals; $86 \%$ overall individual response rate for interview) or who had participated in an eariier alcohol challenge study conducted in 1978-1979 ( $N=412$ individuals; $85 \%$ overall individua response rate for interview; Heath and Martin, 1992; Martin, Oakeshoth. et al., 1985; Martins, Perl, et al., 1985). Telephone interviews were 
completed with 5,889 individuals: ${ }^{1} 2,041$ men (mean age $=42.7$ years, range $=28-89$ ) and 3,848 women (mean age $=44.8$ years, range $=$ 27-90).

There were 2,685 complete twin pairs. Excluding three pairs in which one twin's CD diagnostic data were incomplete, there were 2,682 twin pairs available for analyses of twin similarity for $C D$ ( 930 female monozygotic (MZ) twin pairs, 396 male MZ twin pairs, 533 female-female dizygotic (DZ) twin pairs, 231 male-male DZ twin pairs, and 592 female-male $D Z$ twin pairs).

Preliminary data from an ongoing interview follow-up survey of a subsample of 604 individuals ( 326 men, 278 women) from twin pairs in which at least one twin had a lifetime history of the third revised Diagnostic and Statistical Manual of Mental Disorders (DSM-III-R American Psychiatric Association, 1987) alcohol dependence (assessed at the 1992-1993 interview) were analyzed for the purpose of evaluating the stability of the diagnoses of interest in the present study. The mean age at the 1992-1993 interview for this re-interviewed subsample was 39.4 years (range $=28-73$ ).

Because the ATR is a volunteer twin register, it is possible that twins with a history of $\mathrm{CD}$ (who would be at heightened risk for adult antisocial behaviors) might have been undersampled. Possible sampling biases were examined by (a) comparing demographic and personality characteristics of the baseline sample (participants in the 1980-1981 questionnaire survey) to the interviewed sample, (b) comparing demographic and personality characteristics of twins whose cotwins did not participate in the baseline survey to twins who were concordant for participation in the baseline survey, and (c) comparing rates of $C D$ in twins whose cotwin did not participate in the interview to the rate in twins who were concordant for participation in the interview.

The only demographic or personality characteristics on which the interviewed sample differed by more than $2 \%$ from the baseline sample were the proportion of $\mathrm{MZ}$ twins (men, $40 \%$ at baseline vs. $43 \%$ at interview; women, $49 \%$ at baseline vs. $51 \%$ at interview ), the proportion of respondents bom before 1930 (men, 13\% at baseline vs. 9\% at interview; women, $15 \%$ at baseline vs. $12 \%$ at interview), and the proportion of men with less than 11 years of education (20\% at baseline vs. $16 \%$ at interview). Differences between the baseline and interviewed samples in marital status, religious affiliation, church attendance, and revised Eysenck Personality Questionnaire (EPQ-R; Eysenck, Eysenck, \& Barret, 1985) scale scores were modest.

Another check on sampling bias compared baseline demographic and personality characteristics in twins whose cotwin did not participate at baseline with twins whose cotwin participated at baseline. Assuming that twins are correlated for the baseline demographic and personality characteristics, differences between those who did and did not participate at baseline will be reflected in differences between cotwins of participants and cotwins of nonparticipants. The most consistent predictors of participation at both baseline and interview were being an MZ twin (in both men and women) and having a religious affiliation of "other Protestant" (in women only). There were no consistent associations of participation across surveys with age, education, marital status, church attendance, and personality characteristics.

Similarly, we examined the rates of $C D$ among twins whose cotwin did not participate in the interview and among twins whose cotwin participated in the interview. If twins with $C D$ were systematically undersampled, higher rates of $\mathrm{CD}$ would be expected among twins whose cotwin did not participate in the interview than among twins concordant for participation in the interview (assuming that CD status is correlated in twin pairs). There were 519 twin pairs who were discordant for participation in the telephone interview. The rates of $\mathrm{CD}$ among these unpaired twins did not differ significantly from the rates among the twins concordant for participation, $\chi^{2}(1, N \mathrm{~s}=534-1,970)<1.22, p$ $>.27$ for all six sex by zygosity groups. The combined $C D$ rates across zygosity groups were $18.4 \%$ in concordant men versus $17.4 \%$ in discordant men, $\chi^{2}(1, N=2,041)=0.11, p=.74$, and $2.6 \%$ in concordant women versus $2.8 \%$ in discordant women, $\chi^{2}(1, N=3,842)$ $=0.02, p=.89$.

Heath et al. (1996) examined the impact of cooperation bias and attrition on rates of $C D$ and estimates of genetic and environmental influences on $C D$ liability by weighting the interview data back to the characteristics of the baseline sample and to the distribution of educational attainment found in the general population of Australia. The rates of $C D$ in the weighted data were very similar to the unweighted rates. Overall, the evidence suggests that this sample was not biased with respect to $C D$, although it is likely that severe cases of $C D$ may have been underrepresented in this community-based sample. More important, twin correlations were nearly identical with the weighted and unweighted CD data. The analysis of Heath et al. (1996) suggests that the results of the present study cannot be dismissed solely on the basis of sampling bias.

Australia was the site of penal colonies for more than 168,000 Britist convicts from 1788-1868 (Wheeler, 1989). Despite this, the current crime rates in Australia are not particulariy high compared with Europe, the United States, and Canada (Fingerhut \& Kleinman, 1990; Mukherjee, 1996). In particular, the rates of violent crime such as homicide and robbery are much lower in Australia than in the United States and similar to the rates in England and Canada (Fingerhut \& Kleinman, 1990; Mukherjee, 1996). The rates of nonviolent crimes such as burglary and larceny are roughly similar in Australia, the United States, England, and Canada (Mukherjee, 1996).

\section{Measures}

Measures used in the present study were obtained from two surveys of the ATR. CD was assessed in the telephone interview survey conducted in 1992-1993, and the measures of similarity of childhood experiences and frequency of contact with twin siblings as adults were assessed in the mailed questionnaire survey conducted in 1988-1989.

Zygosity. Twin zygosity diagnoses were based on questionnaire responses concerning physical similarity and how often the twins were mistaken for each other as children. This method of zygosity diagnosis has been shown to be about $95 \%$ accurate, as validated against bloodtyping (Eaves, Eysenck, \& Martin, 1989).

$C D$. The Semi-Structured Assessment for the Genetics of Alcoholism interview (SSAGA; Bucholz et al., 1994a), originally developed for the Collaborative Study on the Genetics of Alcoholism (COGA), was modified for use as a telephone interview in Australia. Interviews were administered by trained lay interviewers who were blind to the psychiatric status of the cotwin. Interviewers were supervised by a qualified clinical psychologist with 4 years of experience who reviewed all interview protocols. In addition, all interviews were tape-recorded and random interview tapes were reviewed for quality control.

Individual $C D$ symptoms were assessed by telephone interview with the modified SSAGA. Participants were asked whether each of the 13 $D S M-I I I-R$ CD symptoms ever occurred before the age of 18 . Individuals who reported that they had the symptom before the age of 18 were asked whether it ever occurred before age 15, and those with 3 or more

\footnotetext{
${ }^{1}$ The reported sample size was 5,995 in previous articles. Subsequently, we discovered that 106 individuals ( 36 twin pairs and 34 single twins) were interviewed who did not meet the criteria for inclusion in the 1992-1993 interview survey. The 106 participants had responded to a mailed questionnaire of the ATR in 1980-1981 but had not participated (nor had their twin participated) in either the alcohol challenge study or the 1988-1989 mailed questionnaire survey. These 106 participants were excluded from the present study. However, when analyses were carried out with the additional participants included, the results did not change from those reported here.
} 
symptoms before age 15 were asked whether they ever had a 6-month period within which at least 3 symptoms co-occurred and persisted. The most common CD symptoms in this community-based sample were as follows: stolen without confrontation on more than one occasion (18\%), often truant from school (15\%), has deliberately engaged in setting fires $(9 \%)$, often lies $(6 \%)$, and has deliberately destroyed other's property $(6 \%)$. Symptoms that were very uncommon in this sample were as follows: stolen with confrontation of a victim $(0.1 \%)$, has forced someone into sexual activity $(0.1 \%)$, and has run away from home overnight at least twice $(0.7 \%)$.

The individual $C D$ symptoms were aggregated into lifetime $C D$ diagnoses by computer algorithm. Three different $\mathrm{CD}$ diagnoses, ranging from a relatively broad to a relatively narrow definition of $C D$ were examined. The focus of the present article was primarily on the broadest definition, which was endorsement of three or more $\mathrm{CD}$ symptoms ever occurring prior to age 18 . This definition corresponds to the DSM-III$R$ CD diagnosis except for the 6-month symptom-duration criterion. The second definition of $C D$ was endorsement of three or more $C D$ symptoms ever occurring prior to age 15; this definition corresponds to the CD criterion for DSM-III-R ASPD. This operationalization of CD, albeit broad, is consistent with that used in the recent National Comorbidity Study (NCS; Cottler, Kessler, \& Nelson, 1995), an epidemiologic psychiatric interview survey of a national probability sample of 15-54 year-old men and women in the United States, and similar to the CD definition used in the Epidemiologic Catchment Area Study (Robins \& Regier, 1991). The third definition of CD was endorsement of three or more $C D$ symptoms occurring prior to age 15 that co-occurred within and persisted for a period of at least 6 months; this definition may correspond to a syndrome more similar to those observed in treatment settings.

The 1-week interrater test-retest reliability (Yule's Y; Spitznagel \& Helzer, 1985) of CD with onset prior to age 15 assessed by the original SSAGA interview was .64-.65 (unpublished data from Bucholz et al, 1994), which is considered "fair" (Fleiss, 1981). Correlations in liability (see below) for this same definition of $C D$ were $.80-.82$ (unpublished data from Bucholz et al., 1994). Stability of the retrospective reports of childhood $\mathrm{CD}$ was assessed in 604 participants from the present study who were re-interviewed on average 15 months later (range $=2-24$ months). The stability of CD with onset prior to age 15 , as indexed by Yule's $Y$ and the correlation in liability, was .76 and .83 and for $C D$ with onset prior to age 18 was .67 and .78 . The 15-month stability of the retrospective reports of childhood CD assessed in these adult participants was as high as the short-term reliabilities obtained for the SSAGA interview.

The use of retrospective assessments of $C D$ in adults represents one of the main limitations of the present study. In fact, any study that assesses ASPD in adults, including the Epidemiologic Catchment Area (Robins \& Regier, 1991) Study and NCS (Kessler et al, 1994), by design faces this limitation because the diagnosis of ASPD requires the diagnosis of childhood CD. Nonetheless, the reliability of such reports is acceptable, and there is evidence to suggest that concurrent (Hindelang, Hirschi, \& Weis, 1981; Hirschi, Hindelang, \& Weis, 1980) and retrospective reports (Henry, Moffit, Caspi, Langley, \& Silva, 1994; Krueger et al., 1994) of delinquent behaviors are also reasonably valid. For example, $73 \%$ of 18 -years-olds with a police record of arrest reported at interview that they had been arrested (Henry et al, 1994). Selfreported history of delinquent activity before age 15 correlated .43 with self-reported police contacts before age 15 retrospectively reported in men 36-55 years of age (Lyons, 1996), compared with a nearly equal correlation of .42 between self-reports of current delinquent activity and a past record of police contacts in 18-year-old men (Krueger et al., 1994). Self-reports of delinquent activity correspond well with official records of delinquent behaviors such as arrests or police contacts.

Similarity of experiences. In the 1988-1989 mailed questionnaire survey, twins were asked how often they shared the same room, had the same playmates, were dressed alike, and were in the same classes at school as children, with the response options of never, sometimes, usually, and always. Twin pairs who responded never or sometimes versus those who responded usually or always were compared in analyses. When twin responses conflicted (i.e., one twin's response was never or sometimes and the other twin's response was usually or always, the twin pair was placed in the never or sometimes category. In addition, twins were asked how often they currently saw or contacted their twin, and two dichotomous variables were created from the responses. Twins who currently saw each other at least once a week were contrasted with those who saw each other less frequently. Similarly, twins who currently contacted each other by telephone or letter at least once a week were contrasted with those who were in less frequent current contact.

\section{Data Analysis}

Two indexes of twin similarity for $C D$ were computed: the probandwise concordance and the tetrachoric correlation. The probandwise concordance is an estimate of the probability that an individual has a $C D$ diagnosis given that their cotwin has the diagnosis and is computed with only twin pairs with at least one affected member. The tetrachoric correlation, or correlation in liability (Olsson, 1979), is computed from the full two-by-two contingency table cross-classifying the $C D$ status of a twin by the $C D$ status of the cotwin. The tetrachoric correlation is used when one assumes that scores on the observed ordinal variables can be explained by underlying normally distributed variables (Falconer, 1965; Gottesman \& Shields, 1967; Reich, Cloninger, \& Guze, 1975). In this case, the continuum underlying $C D$ diagnostic status was presumed to be the liability to develop $\mathrm{CD}$; participants were assigned a positive or negative $C D$ diagnosis on the basis of whether or not their CD liability exceeded some arbitrary criterion or threshold (see Figure 1a). The tetrachoric correlation is the correlation between the presumed normally distributed latent $C D$ liability between twin pairs.

In addition to $D S M-I I I-R C D$ and the childhood criterion for DSM$I I-R$ ASPD, we carried out twin analyses for a multiple-threshold model (Reich, James, \& Morris, 1972) of CD liability (see Figure 1b). To test whether subclinical manifestations of $\mathrm{CD}$ (i.e., one or two $\mathrm{CD}$ symptoms endorsed) lie on the same liability dimension as the diagnosable disorder, the polychoric correlation (the generalization of the tetrachoric correlation coefficient for polychotomous variables of three or more categories) between the number of $\mathrm{CD}$ symptoms (i.e., zero, one, two, or three or more symptoms) within twin pairs was calculated from the $4 \times 4$ contingency tables using PRELIS (Joreskog \& Sorbom, 1988). The assumption of an underlying distribution of liability was tested by comparing the observed frequencies in the $4 \times 4$ contingency tables with the frequencies expected assuming bivariate normal distributions of the underlying latent liability (Neale \& Cardon, 1992). The results of these chi-square tests are presented, although they should not be overinterpreted because the statistical power to detect deviations from bivariate normality in ordinal data from a general population sample is low (Neale, Eaves, \& Kendler, 1994).

Genetic and environmental structural equation models were fitted directly to the five twin contingency tables by maximum likelihood using the Mx program (Neale, 1995) to determine the relative roles of additive genetic (A), shared environmental (C; i.e., between family or common environment), and nonshared environmental (E; i.e., within family or individual-specific environment including measurement error) factors as sources of variation for $C D$ liability. The fit of a series of nested submodels was compared by likelihood ratio chi-square to a most general full model, which allowed for additive genetic, shared environmental, and nonshared environmental factors as sources of variation (ACE model). For example, models in which the genetic influences (or shared environmental influences) were fixed at zero were compared with the model 

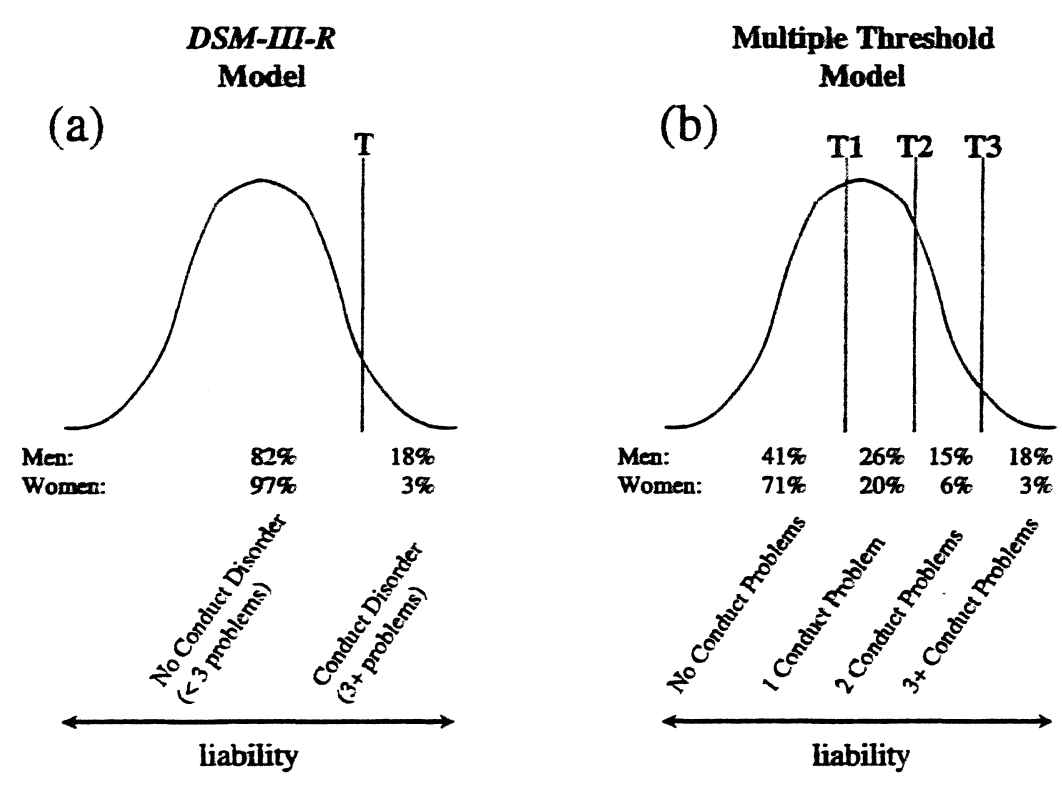

Figure 1. (a): Liability threshold model of Diagnostic and Statistical Manual of Mental Disorders (DSMIII-R; American Psychiatric Association, 1987) conduct disorder. Under this model, it is hypothesized that $D S M-I I I-R$ conduct disorder is due to the cumulative influence of many genetic or environmental risk factors, each of relatively small effect, and that the liability to develop $D S M-I I-R$ conduct disorder is normally distributed in the general population. Individuals whose liability exceeds the threshold value (T) will be affected with $D S M-I M-R$ conduct disorder. Thresholds may differ for men and women. (b): Multiple-threshold liability model of conduct disorder, similar to the model presented in 1a. In addition, under this model, it is hypothesized that subclinical manifestations of conduct disorder lie on the same liability dimension and share the same risk factors as the diagnosed disorder Individuais whose liability exceeds the first threshold (T1) will manifest at least one conduct problem; those whose liability exceeds the second threshold (T2) will manifest at least two conduct problems; and those whose liability exceeds the third threshold value (T3) will manifest three or more conduct problems. Again, thresholds may differ for men and women. Percentages listed under each distribution are the observed prevalences of each diagnostic category in the sample of adult Australian men $(n=2,041)$ and women $(n=3,848)$.

containing all three sources of variation. When dropping parameters from a model did not result in a statistically significant decrement in model fit (i.e., there was a nonsignificant likelihood ratio chi-square test), then the reduced model was considered to give a better (i.e., more parsimonious) fit to the data. The final best fit model was the simplest model that was consistent with the data (see Heath et al., 1989; Neale \& Cardon, 1992, for further details about model fitting). The overall adequacy of the fit of a particular model to the data was assessed by the goodness-of-fit chi-square test. Unlike most significance testing in psychological research, the goal is to obtain a nonsignificant goodnessof-fit chi-square; this indicates that the model cannot be rejected because it provides an adequate explanation of the covariance structure in the data. Genetic and environmental model fitting was carried out for DSM$I I I-R C D$ diagnoses and for a multiple-threshold model of $C D$ liability

Model fitting with data that included both male and femaie and unlikesex twin pairs permitted tests of several hypotheses about possible sex differences in the etiology of $\mathrm{CD}$. First, we tested whether the magnitude of genetic and environmental influences on $\mathrm{CD}$ liability differed in men and women. This was evaluated by comparing the fit of a model that allowed genetic and environmental parameter estimates to vary between men and women with the fit of a model that constrained genetic and environmental parameter estimates to be equal in the two sexes. Second, we tested whether the genetic and shared environmental mechanisms that influence the development of $C D$ differed in men and women by testing whether the genetic correlation in unlike-sex twin pairs $\left(\mathrm{r}_{\mathrm{A}}\right)$ was significantly different than the .50 that is expected for traits in which there is no sex limitation of genetic influences (while fixing the shared environmental correlation at 1) and, similarly, testing whether the shared environmental correlation in unlike-sex twin pairs $\left(r_{C}\right)$ was significantly different from the 1 that is assumed for traits in which there are not sex-specific shared environmental influences (while fixing the genetic correlation at .5). Note that either $r_{A}$ or $r_{C}$ can be freely estimated in these models, but it is not possible to freely estimate both parameters simultaneously with data from $\mathrm{MZ}$ and $\mathrm{DZ}$ twins.

Confidence intervals for parameter estimates of additive genetic, shared environmental, and nonshared environmental effects were computed in Mx by determining the upper and lower bounds of a parameter that produced a statistically significant deterioration in model fit. This was done by fixing a parameter and comparing, by the likelihood ratio chi-square test, the fit of the model with the fixed parameter to the fit of the model in which the parameter was freely estimated. In the present article, $95 \%$ confidence limits of parameter estimates are presented for both the full and best-fit models. For both the full and best-fit models, confidence limits were computed within a saturated model that included all three sources of variation (additive genetic, shared environmental. and nonshared environmental influences). Confidence limits were computed separately for men and women for parameter estimates obtained under the full models; for best-fit models, confidence limits of parameter estimates were computed separately for men and women only if there was evidence for sex differences in the parameter estimate, otherwise confidence intervals were computed jointly for men and women.

This method of computing confidence intervals is preferred to comput- 
ing the confidence interval as 1.96 times the standard error of the parameter estimate, because the standard error method assumes that the distribution of the parameter estimate is normal. In model fitting of twin data, the distribution of the paramete estimates are often skewed, resulting in confidence intervals that are asymmetrical around the parameter estimates.

MZ twins typically have more similar experiences than $D Z$ twins; for example, they more frequently share playmates as children and are in more frequent contact as aduhs (Kendler, 1993). If such experiences are relevant to the development of $\mathrm{CD}$, then the equal environmental similarity assumption of twin swudies may not be correct for this disorder (Kendler, 1993; Kendler, Neale, Kessler, Heath, \& Eaves, 1993). To test the equal environmental similarity assumption, logistic regression analyses predicting twin concordance for CD from similarity of childhood experiences were performed, controlling for zygosity, sex, and age. Because the assessment of $C D$ was based on retrospective reports of the twins as adults, we also examined whethe frequency of contact as adults predicted twin concordance for $C D$ in similar logistic regression analyses.

\section{Results}

\section{Lifetime Prevalence of $C D$}

The prevalence of a self-reported childhood history of DSM$I I I-R$ CD was $18 \%$ in men and $3 \%$ in women. The sex difference in the rate of $C D$ was highly significant, $\chi^{2}(1, N=5,883)$ $=440.5, \mathrm{p}<.001$. History of $D S M-I M-R C D$ also varied by birth cohort in both men, $\chi^{2}(4, N=2,041)=34.7, p<.001$, and women, $\chi^{2}(4, N=3,842)=37.3, p<.001$, with rates ranging from $22 \%$ and $5 \%$ in men and women under age 35 , to $7 \%$ and $0.2 \%$ in men and women aged 60 years and older. The lifetime prevalence of $\mathrm{CD}$ with onset prior to age 15 was $13 \%$ in men and $2 \%$ in women, and when the requirement of a 6 month period of symptom clustering was imposed, the rates of $\mathrm{CD}$ fell to $4 \%$ in men and $0.6 \%$ in women. There were too few cases of $C D$ with onset prior to age 15 and a 6 -month period of symptom clustering to carry out analyses of twin similarity or genetic and environmental model fitting for this definition of $\mathrm{CD}$, so for the remainder of this article only the two broader definitions of $C D$ are used. We chose to focus primarily on the broadest definition of $D S M-I I-R C D$ because of the advantage of increased statistical power and doubts about participants' ability to recall accurately information about the age of onset of symptoms over such long time intervals (on average a minimum of 25 years).

The rates of CD for Australian men and women in the present study were somewhat lower than rates reported for the general population of the United States in the NCS. Cottler, Kessler, and Nelson (1995) reported lifetime prevalence estimates of the childhood criterion for $D S M-I I I-R$ ASPD (i.e., CD with onset prior to age 15 ) of $20 \%$ in men and $6 \%$ in women, compared with rates of $13 \%$ and $2 \%$ for the comparable definition of $C D$ in this Australian sample. However, the older average age of this sample, compared with the NCS sample, may have contributed to the differences in $\mathrm{CD}$ rates. Once age was taken into consideration, the rate of $C D$ in this Australian sample did not consistently differ with rates estimated for the general population of the United States. The rates of CD in the NCS study were $18 \%$ in men aged $35-44$ years and $13 \%$ in men aged $45-54$ years; in the Australian sample, the rates of $\mathrm{CD}$ before age 15 for men in these age groups were $15 \%$ and $14 \%$. The rates of $C D$ in the NCS study were $3 \%$ in women aged $35-44$ years and $3 \%$ in women aged 45-54 years; in the Australian sample, the rates of $\mathrm{CD}$ before age 15 for women in these age groups were $2 \%$ and $2 \%$. Only the rate in women $35-44$ years of age was significantly different in the present sample compared with the rate in the NCS.

\section{Twin Similarity for $C D$}

Probandwise concordances and correlations in liability for $D S M-I I I-R C D$ are presented in Table 1 . The $\mathrm{MZ}$ concordance was higher than the $\mathrm{DZ}$ concordance in both men (.53 vs. .37) and women ( .30 vs. .18 ), but the difference attained statistical significance in men only, men: $\chi^{2}(1)=6.2, p=.01$; women: $\chi^{2}(1)=1.4, p=.24$. Similarly, the correlations in liability for $D S M-I I I-R$ CD were higher among $\mathrm{MZ}$ than among $\mathrm{DZ}$ twins, but significantly so only among men, men: .70 vs. $.37, \chi^{2}(1)$ $=6.7, p=.01$; women: .68 vs. $.48, \chi^{2}(1)=1.2, p=.28$. Correlations in liability for $\mathrm{CD}$ with an onset prior to age 15 were all within a standard error of the correlations in liability for $D S M-I I I-R C D$ and had a similar pattern of $M Z-D Z$ differences.

\section{Sex Differences}

Examination of the tetrachoric correlations in Table 1 suggests that the magnitude of genetic and environmental influences for $\mathrm{CD}$ do not differ in boys and girls. The tetrachoric correlations for $D S M-I I I-R C D$ in male versus female $\mathrm{MZ}$ twin pairs did not differ significantly, .70 vs. $.68, \chi^{2}(1)=0.03, p=.87$, nor did the correlations in the same-sex male, female, and unlike-sex $\mathrm{DZ}$ twin pairs, .37 vs. .48 vs. $.34, \chi^{2}(2)=0.44, p=$ .80 . In addition, the ratio of the unlike-sex DZ twin correlation to the geometric mean of the same-sex DZ correlations (see Cloninger et al., 1978) indicates that most of the familial influences relevant to the development of $C D(81 \%)$ are shared by boys and girls. More rigorous tests of sex differences in the etiology of $\mathrm{CD}$ with model-fitting methods are presented below.

\section{Fit of the Multiple-Threshold Model}

Figure 1b presents the observed prevalences of each of the categories (zero, one, two, or three or more conduct problems) used for the multiple-threshold model of $\mathrm{CD}$ for men and women, and the correlations in liability for the multiple-threshold model are presented in Table 1 . The twin correlations for the multiple-threshold model were slightly reduced compared with the correlations in liability for $D S M-I I I-R C D$. In all five zygosity groups, the assumption of a bivariate normal liability distribution underlying the four ordered $C D$ categories could not be rejected by a goodness-of-fit chi-square test.

\section{Genetic and Environmental Model Fitting: DSM-III-R CD}

A full model allowing for additive genetic, shared environmental, and nonshared environmental influences for DSM-III$R \mathrm{CD}$ fit the data well, goodness-of-fit $\chi^{2}(4)=5.51, p=.24$, and yielded heritability estimates of $65 \%$ in men and $43 \%$ in 
Table 1

Prevalence and Twin Similarity for History of Conduct Disorder in Australian Men and Women

\begin{tabular}{lccccc}
\hline \multicolumn{1}{c}{ Zygosity group } & $n$ pairs & $\begin{array}{c}\text { Prevalence } \\
(D S M-I I-R)\end{array}$ & $\begin{array}{c}\text { Probandwise } \\
\text { concordance } \\
(D S M-I I I-R)\end{array}$ & $\begin{array}{c}\text { Tetrachoric } \\
\text { correlation } \\
(D S M-I I-R)\end{array}$ & $\begin{array}{c}\text { Polychoric } \\
\text { correlation } \\
\text { (multiple threshold) }\end{array}$ \\
\hline MZ male & 396 & $.17(.01)$ & $.53(.04)$ & $.70(.06)$ & $.52(.05)$ \\
DZ maile & 231 & $.20(.02)$ & $.37(.05)$ & $.37(.12)$ & $.29(.08)$ \\
MZ female & 930 & $.02(.00)$ & $.30(.07)$ & $.68(.10)$ & $.63(.04)$ \\
DZ female & 533 & $.03(.01)$ & $.18(.07)$ & $.48(.16)$ & $.41(.06)$ \\
DZ umlike-sex (all) & 592 & $.03(.01)$ & $.08(.03)$ & $.34(.12)$ & $.31(.05)$ \\
DZ female cotwin of male proband & & $.19(.02)$ & $.45(.11)$ & & \\
DZ male cotwin of female proband & & & & \\
\hline
\end{tabular}

Note. Standard errors are in parentheses. $D S M-I I I-R=$ Diagnostic and Statistical Manual of Mental Disorders (American Psychiatric Association. 1987); $M Z=$ monozygotic; $D Z=$ dizygotic.

women and estimates of shared environmental influences of $4 \%$ in men and $25 \%$ in women ( see Table 2 ). Setting the prevalences (i.e., threshold values) for $\mathrm{CD}$ to be equal in $\mathrm{MZ}$ male, $\mathrm{DZ}$ male, and males from unlike-sex pairs and, similarly, $M Z$ female, $D Z$ female, and females from unlike-sex pairs did not result in a significant deterioration in model fit, $\chi^{2}(4)=4.71, p=.32$, and therefore, in all subsequent models, thresholds were constrained to be equal across zygosity groups. As expected, setting the prevalences for $C D$ to be equal in men and women resulted in a substantial deterioration in model fit, $\chi^{2}(1)=308.80, p$ $<.001$; therefore, separate threshold values were estimated for men and women in all subsequent models.

When we fitted a full model allowing for sex differences in the etiology of $D S M-I I I-R C D$, estimates of either the betweensex genetic correlation $\left(r_{\mathrm{A}}\right)$ or the shared environmental correlation $\left(r_{c}\right)$ were .44 and .56 , respectively. Nonetheless, there was not a significant deterioration in model fit when the estimate of $r_{\mathrm{A}}$ was fixed at $.5, \chi^{2}(1)=0.01, p=.93$ or the estimate of $r_{\mathrm{C}}$ was fixed at $1, \chi^{2}(1)=0.01, p=.93$, and so in subsequent models $r_{\mathrm{A}}$ and $r_{\mathrm{C}}$ were fixed at these values. Setting equal the estimates of additive genetic, shared environmental, and non- shared environmental influences for men and women also dio not result in a significant deterioration in model fit, $\chi^{2}(2)=$ $0.37, p=.83$; subsequent models constrained these estimates to be equivalent across sex. In sum, although inspection of the twin correlations suggested that there might be sex differences in the magnitude of genetic and environmental influences and in the specific additive genetic and shared environmental mechanisms that are important for the development of $D S M-I I I-R$ $C D$, these sex differences were not statistically significant.

The fit of reduced models that accounted for $D S M-I I I-R$ $C D$ liability by the action of nonshared environmental influences only (E), shared and nonshared environmental influences (CE), and additive genetic and nonshared environmental influences (AE) were compared with the fit of a full model that included all three sources of variation (ACE). The E model, goodnessof-fit $\chi^{2}(13)=118.90, p<.001$, and the CE model, goodnessof-fit $\chi^{2}(12)=23.98, p=.02$, were both rejected by goodnessof-fit and likelihood ratio tests. In other words, genetic influences could not be dropped without a significant deterioration in model fit, $\chi^{2}(1)=13.38, p<.001$. Eliminating shared environmental influences did not result in a significant deteriora-

Table 2

Model-Fitting Results for Conduct Disorder

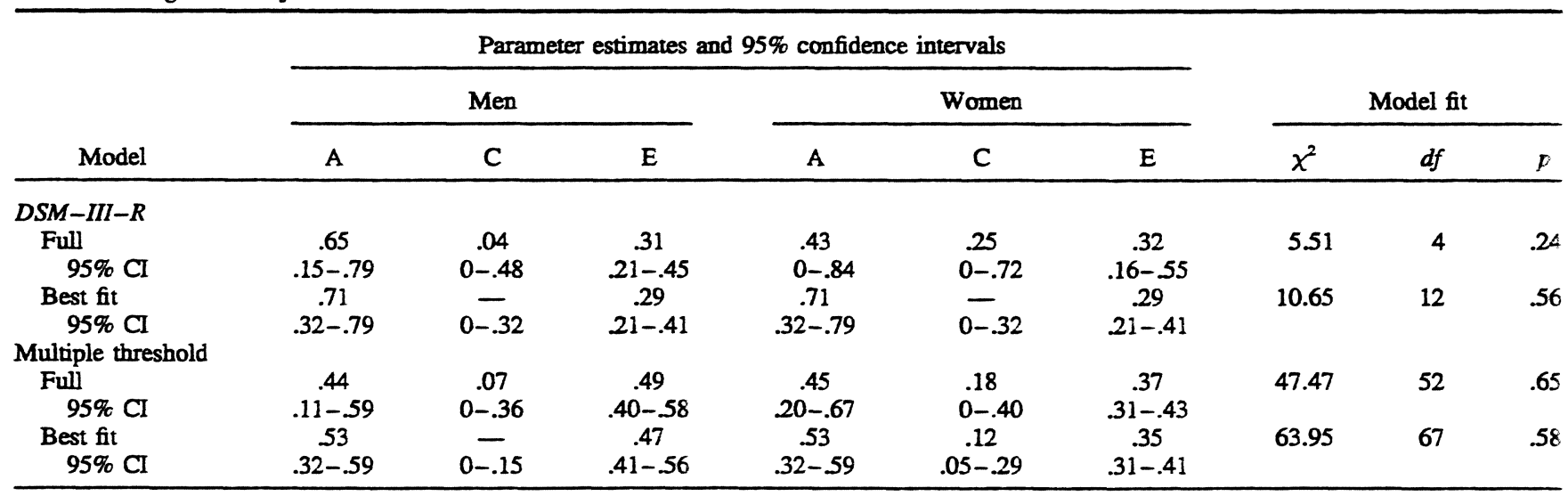

Note. Dashes indicate that the parameter was dropped from the model. $A=$ additive genetic effects; $C=$ shared environmental effects; $E=$ nonshared environmental effects; $D S M-I I I-R=$ Diagnostic and Statistical Manual of Mental Disorders (American Psychiatric Association, 1987); $\mathrm{CI}=$ confidence interval. Note that a nonsignificant goodness-of-fit chi-square indicates that the model provides an adequate fit to the data. 
tion in model fit, $\chi^{2}(1)=0.05, p=.82$. A model that included additive genetic and nonshared environmental influences (AE) fit the data well, goodness-of-fit, $\chi^{2}(12)=10.65, p=.56$, and was retained as the best-fitting model. The best-fitting model yielded variance estimates for additive genetic influences of $71 \%$ ( $95 \%$ confidence interval $=32-79 \%$ ), for shared environmental influences of $0 \%$ ( $95 \%$ confidence interval $=0-32 \%$ ), and for nonshared environmental influences of $29 \%$ (95\% confdence interval $=21-41 \%){ }^{2}$

Although not a primary focus in the present study, the effect of birth cohort was examined to determine whether it was an important source of variation for $C D$ or a moderator of genetic and environmental influences on $\mathrm{CD}$. When birth cohort was included in a full model, it accounted for $1 \%$ of the variance in $\mathrm{CD}$ liability in men (the estimates of the remaining variance components in the full model including birth cohort effects were as follows: A: $69 \%, \mathrm{C}: 2 \%$, and $\mathrm{E}: 28 \%$ ) and $7 \%$ of the variance in women (A: $46 \%, C: 17 \%$, and $E: 30 \%$ ). When the magnitude of genetic and environmental influences were estimated separately for different birth cohorts, the parameter estimates were not significantly different across cohorts, $\chi^{2}(8)=12.03, p=$ .15. In sum, birth cohort significantly contributed to the variation in liability for $C D$ in the present sample but was not a significant moderator of genetic and environmental influences on risk for $\mathrm{CD}$. Because the effect of birth cohort was relatively modest, models without birth cohort are reported in this article to simplify presentation. Note that the effect of birth cohort when not separately estimated, will contribute to the estimate of shared environmental influences. Consequently, about one half of the estimated shared environmental influences for $C D$ liability in men and about one third of the estimated shared environmental influences for CD liability in women in the full model in Table 2 can be attributed to birth cohort effects.

Model fitting for $C D$ with onset prior to age 15 (the age corresponding to the childhood criteria for DSM-III-R ASPD) yielded very similar results as obtained for $C D$ with onset prior to age 18, with the same estimates of additive genetic and nonshared environmental variances ( $71 \%$ and $29 \%$, respectively) in the best-fitting model.

\section{Genetic and Environmental Model Fitting: Multiple- Threshold Model of $C D$}

The full and best-fitting models for the multiple-threshold model of $\mathrm{CD}$ liability are also presented in Table 2 . The full ACE model fit the data well, goodness-of-fit $\chi^{2}(52)=47.47$, $p=.65$, and yielded parameter estimates that were close to those for $D S M-I I-R$ CD liability, except that the estimate of additive genetic influences was somewhat reduced in men. The estimates of the between-sex genetic and environmental correlations were .46 and .80 , respectively; these values were not significantly different from $.5, \chi^{2}(1)=0.03, p=.87$, and $1, \chi^{2}(1)$ $=0.03, p=.87$. Thus, there was little evidence to suggest that the specific genetic and environmental mechanisms associated with $\mathrm{CD}$ liability differed in men and women. However, a model that did not allow for sex differences in the estimates of the relative magnitude of additive genetic, shared environmental, and nonshared environmental influences (ACE model), goodness-of-fit $\chi^{2}(67)=70.17, p=.37$, was rejected compared with a model that included sex-specific parameter estimates, $\chi^{2}(2)=7.30, p=.03$.

We attempted to identify the most parsimonious sex-limitation model that could account for the data. A model that allowed for sex differences in parameter estimates but ruled out the influence of additive genetic factors $\left(C_{m} C_{f} E_{m} E_{f}\right.$ model, where $m=$ male and $_{\mathrm{f}}=$ female), was rejected by both goodness-offit, $\chi^{2}(67)=98.39, p=.01$, and likelihood ratio test. In other words, additive genetic influences could not be dropped from the model without a significant deterioration in fit, $\chi^{2}(2)=$ $35.52, p<.001$. Two parsimonious models fit the data without a significant deterioration in fit; an $A_{m} A_{f} E_{m} E_{f}$ model, goodnessof-fit $\chi^{2}(67)=64.86 p=.55$, and an $A_{m f} C_{f} E_{m} E_{f}$ model, goodness-of-fit $\chi^{2}(67)=63.95, p=.58$. Because the fit of the latter model was slightly superior to the former, it is presented in Table 2 as the best-fitting model. The main difference in the parameter estimates between the two models was in the amount of variance apportioned to additive genetic and shared environmental influences in women; the parameter estimates for men were nearly identical for the two models (A: $53 \%$ vs. $52 \%$, E: $47 \%$ vs. $48 \%$ ). The best-fitting model for the multiple-threshold model of CD liability suggested that the magnitude of additive genetic influences were equal in men and women, accounting for $53 \%$ of the variance and that shared environmental influences were important only in women, accounting for $12 \%$ of the variance, with $35 \%$ of the variance in women accounted for by nonshared environmental influences. In the alternative model, additive genetic influences accounted for $66 \%$ and nonshared environmental influences accounted for $34 \%$ of the variation in $\mathrm{CD}$ liability in women.

\section{Testing Assumptions of the Twin Method}

The rate of $D S M-I I I-R C D$ did not vary as a function of zygosity, women: $\chi^{2}(2)=5.5, p=.06$; men: $\chi^{2}(2)=2.2, p$ $=.33$, which suggests that $\mathrm{MZ}$ and $\mathrm{DZ}$ twins do not differ in their risk for developing $C D$. Nonetheless, $M Z$ twins reported more similar childhood experiences and more frequent contact as adults than $\mathrm{DZ}$ twins (e.g., $83 \%$ of female $\mathrm{MZ}$ twins usually or always shared the same playmates as children compared with $50 \%$ of like-sex female DZ twins). We examined whether this increased similarity of childhood experiences was associated with twin similarity for $D S M-I I I-R C D$. After controlling for zygosity, sex, and age, sharing the same room as children, $\chi^{2}(1)$ $=1.2, p=.27$, dressing alike as children, $\chi^{2}(1)=0.94, p=$ .33 , and being in the same classes in school as children, $\chi^{2}(1)$ $=2.4, p=.12$, did not significantly predict twin concordance for $D S M-I I I-R C D$. There was a positive association, however, between sharing the same playmates as children, $\chi^{2}(1)=5.2$, $p=.02$, and twin similarity for $D S M-I I I-R C D$. In addition,

\footnotetext{
${ }^{2}$ The robustness of the best-fitting model choice was checked by repeating the model fitting with a different order to test for the significance of parameters. Thus, in addition to the procedure outlined in detai in the text, we also tested the significance of the genetic and shared environmental variance components prior to setting these parameter estimates equal in men and women. The conclusions and the best-fitting model remained the same regardless of the order of dropping nonsignificant parameters.
} 
the frequency with which twins saw each other, $\chi^{2}(1)=4.6$, $p=.03$, and contacted each other by telephone or letter, $\chi^{2}(1)$ $=4.9, p=.03$, as adults was also associated with twin similarity for $D S M-I I I-R \mathrm{CD}$.

To shed more light on this issue, we examined the same-sex twin correlations stratified by similarity of experience. Among men, $\mathrm{MZ}$ twins who more often shared the same friends as children were more similar than $\mathrm{MZ}$ twins who less often shared the same friends, .76 versus $.30, \chi^{2}(1)=4.62, p=.03$, but there was no difference in the similarity of $D Z$ twins stratified by the frequency of sharing childhood peers, .46 versus 28 , $\chi^{2}(1)=0.57, p=.45$. When MZ-DZ comparisons conditional on sharing childhood peers were made, $M Z$ twins who less often shared the same friends as children were no more similar than $\mathrm{DZ}$ twins who less often shared the same friends as children, .30 versus $.28, \chi^{2}(1)=0.00, p=.96$, but there was a significant MZ-DZ difference among those twin pairs who more often shared the same friends as children, .76 versus $.46, \chi^{2}(1)=$ 4.06, $p=.04$. Among male $\mathrm{DZ}$ twins, those who were more often in the same classes as children were more similar than those who were in the same classes less often, .72 versus .18 , $\chi^{2}(1)=5.76, p=.02$, but there were no differences among the $\mathrm{MZ}$ twin pairs, .72 versus $.64, \chi^{2}(1)=0.28, p=.60 . \mathrm{MZ}$ twins were more similar than $\mathrm{DZ}$ twins among those who were in the same classes less often, .64 versus $.18, \chi^{2}(1)=4.28, p$ $=.04$, but not among those who were more often in the same classes, .72 versus $.72, \chi^{2}(1)=0.00, p=.99$. Among women, there were significant differences among $M Z$ twins who differed in how often they dressed alike and were in the same classes as children, but these differences were opposite to what would be expected if greater similarity of experience leads to greater twin similarity for $C D$, that is, female twins who reported that they more often dressed alike or were in the same classes as children were less similar than those who reported that they less often dressed alike or were in the same classes.

In sum, these results suggest that, at least in men, the equal environmental similarity assumption may not be correct for twin studies of $C D$ and that estimates of the genetic influences on $C D$ should be interpreted with this caveat in mind. Although controlling for similarity of childhood experiences (namely, sharing the same friends and being in the same classes as children) effectively eliminated $M Z-D Z$ twin differences in some subsamples, $M Z-D Z$ differences remained significant in others. Even though genetic influences may be, to some extent, confounded with the greater environmental similarity of $M Z$ than DZ twin pairs, genetic influences still are an important contributor to twin similarity for $C D$ after controlling for the environmental similarity of twins. We discuss this issue further below.

\section{Discussion}

In a large community sample of adult Australian twins, we found evidence for a substantial genetic influence on the risk for $D S M-I I I-R C D$. The best-fitting model yielded a point estimate of heritability of $71 \%$, with a $95 \%$ confidence interval of $32-79 \%$. There was not a statistically significant effect of the shared environment in the best-fitting model of $\mathrm{CD}$, but a modest effect of the shared environment on the risk for $\mathrm{CD}$ could not be excluded ( $95 \%$ confidence interval $=0-32 \%$ ).
One point that should be emphasized is the lack of precision with which parameters such as heritability are estimated for psychiatric disorders (or any categorical trait with a prevalence substantially different from $50 \%$ ), even with sample sizes as large as 2,682 twin pairs (Neale, Eaves, \& Kendler, 1994). The heritability value itself should not be overly emphasized but rather the undeniable importance of genetic factors in the development of CD.

Although there was not a statistically significant effect of the shared environment in the development of $D S M-I I-R C D$ in the present study, shared environmental influences still may have accounted for up to $32 \%$ of the variation in liability. Twin studies can have limited power to detect the effect of the shared environment when it is estimated as a latent variable (i.e., inferred from the pattern of correlations in $\mathrm{MZ}$ and $\mathrm{DZ}$ twins) but can detect relatively modest effects of the shared environment when specific environmental risk factors are measured and included in the model fitting of twin data. For example, when childhood parental loss and separation was measured as a specific environmental risk factor, it accounted for a modest, but statistically significant, $2-5 \%$ of the variation in liability to anxiety disorders, depression (Kendler, Neale, Kessler, Heath, \& Eaves, 1992), and alcoholism (Kendler et al., 1996) in women. Similarly, in the present study, there was a statistically significant effect of birth cohort, accounting for $1 \%$ and $7 \%$ of the variation in CD liability in men and women. Thus, although the overall effect of the shared environment was not statistically significant, the effect of a specific environmental risk factor significantly contributed to the variation in liability to develop $C D$. A substantial portion (30-50\%) of the effect of the shared environment appeared to be due to differences in risk of $C D$ for individuals growing up in different eras. With these cross-sectional data, it is unclear whether this effect represents true changes in the rates of $C D$ in more recent eras or simply poorer recall of childhood misbehavior in older twins. Increased rates of self-reported CD in more recent birth cohorts in Australia are consistent with official statistics that document rises in crime (Biles, 1983; Mukherjee, 1996). Therefore, it is possible that sociocultural changes may be leading to increased risk for antisocial behaviors in youth.

The results of the present study agree with those of Rowe's (1983) twin study of self-reported delinquency in mostly school-ascertained adolescents but conflict with a recent large twin study of $C D$ retrospectively assessed in adult men (Lyons et al., 1995) that found a modest genetic effect and substantial shared environmental influences. The Vietnam-era twin panel sample, used in the Lyons et al. (1995) study, was identified from twin pairs in which both twins had been accepted for military service during the Vietnam era. Most participants in the Vietnam-era sample had completed high school, and only 9\% met the childhood criteria for DSM-III-R ASPD (i.e., CD with onset prior to age 15), a much lower rate than is obtained in general population surveys of adults in the United States (Cottler, Kessler, \& Nelson, 1995) and significantly lower than the rate of $14 \%$ of $C D$ before age 15 in men from the same age range in the present study, $\chi^{2}(1, N=7,506)=27.81, p<$ .001 . The selected nature of the Vietnam-era twin panel may explain the markedly different results obtained in these studies. In addition, it is interesting to note that although there were not 
substantial genetic influences for $D S M-I I-R$ conduct problems in the Vietnam-era sample, genetic influences accounted for $39 \%$ of the risk of being arrested prior to age 15 (Lyons, 1996).

Previous (nontwin) research has suggested that the causes of CD may differ in boys and girls (Goodman \& Kohlsdorf, 1994; Rutter \& Giller, 1983), and some twin studies suggest that the magnitude of genetic influences for $C D$ may be greater in boys than in girls. In the present study, there was little evidence for sex differences in the etiology of $\mathrm{CD}$. The magnitude of genetic and environmental infiuences for $D S M-I I I-R C D$ did not vary significantly in men and women. In addition, the genetic and environmental mechanisms important for the development of $\mathrm{CD}$ appeared to be largely the same for both sexes.

In the present study, a multiple-threshold model of $C D$ liability fit the data. This suggests that $C D$ may not necessarily be a discrete entity but rather an extreme of the normal variation in conduct-disordered behavior found in the general population. The fit of this model suggests that the risk factors for and correlates and consequences of normal-range or subclinical forms of childhood antisocial behaviors are the same as those for $C D$. This is consistent with reports from the Epidemiologic Catchment Area Study (Robins \& Regier, 1991), in which the number of childhood CD symptoms functioned as a continuum in predicting adult antisocial behaviors (Robins \& Price, 1991; Robins, Tipp, \& Przybeck, 1991), drug use (Robins \& McEvoy, 1990), age of onset of alcohol and drug use (Robins \& McEvoy, 1990), substance abuse (Robins \& McEvoy, 1990), alcohol and drug abuse or dependence (Robins \& Price, 1991), anxiety disorders (Robins \& Price, 1991), somatization disorder (Robins \& Price, 1991), depression (Robins \& Price, 1991), and schizophrenia (Robins \& Price, 1991). Results of studies of symptom counts of antisocial, delinquent, or externalizing behaviors can probably be generalized to $\mathrm{CD}$. This alternative approach to assessing childhood antisocial behaviors has the advantage that it uses more of the available information in the data (i.e., the number of different behaviors rather than whether or not the child has exceeded a single diagnostic threshold) and, thus, has increased statistical power (Neale, Eaves, \& Kendler, 1994). For example, in the current study, the $95 \%$ confidence intervals for parameter estimates under the multiple-threshold model were much narrower than under the $D S M-I I I-R$ model.

Even though this study suggests that $C D$, for the most part. can be thought of as the extreme of a continuum of childhood antisocial behavior, this does not rule out the possibility of etiologically distinct forms of $\mathrm{CD}$. Community-based studies may have limited power to detect etiologically distinct but relatively rare forms of a disorder as being discontinuous with more common forms of the disorder. For example, severe physical or sexual abuse or other trauma may cause CD in the absence of genetic vulnerability, or severe CD may be etiologically distinct from less severe forms of $C D$. Furthermore, although the multiple-threshold model of $C D$ liability could not be rejected, we found that the correlation in $\mathrm{MZ}$ men was somewhat reduced for the multiple-threshold model compared with the DSM-III$R$ model of $\mathrm{CD}$, resulting in a lower estimate of genetic influences for $C D$ in men. This suggests the possibility that there may be unique genetic influences, in addition to those that contribute to normal-range variation in childhood antisocial behaviors, that predispose to diagnosable $C D$ in boys. Hierarchical genetic models, such as those proposed for examining the genetic architecture of smoking initiation and persistence (Heath \& Martin, 1993), may be useful to further explore this question. ${ }^{3}$

\section{Validity of Twin Method Assumptions}

The results of the present study must be evaluated with the assumptions of the twin method in mind. Although there is ample evidence for the validity of these assumptions for many psychological domains (Kendler, 1993; Plomin, DeFries, \& McClearn, 1990), it is worthwhile to consider the assumptions of the twin method specifically with respect to childhood $C D$.

The first assumption of the twin method that must be considered is whether twins are representative of the general (nontwin) population with respect to $C D$ or, more broadly, with respect to possible risk factors for $\mathrm{CD}$. There is some evidence to suggest that there is a slight excess of CD or similar behavioral problems in twins compared with singletons, both in community and psychiatric samples (Gau, Silberg, Erickson, \& Hewitt, 1992; Rutter \& Redshaw, 1991; Simonoff, 1992), although van den Oord, Koot, Boomsma, Verhulst, and Orlebeke (1995) found lower levels of mother-rated oppositional behaviors in preschool twins compared with singletons. In addition, twins have slightly lower IQ scores than singletons on average and are more likely to have pre- and perinatal birth complications, language difficulties (Rutter \& Redshaw, 1991; Simonoff, 1992), and depressed mothers (Thorpe, Golding, MacGillivray, \& Greenwood, 1991). These findings are consistent with and may, in part, explain the slight excess of childhood antisocial behaviors in twins compared with singletons. The generalizability of twin studies of childhood psychopathology is still a matter open to debate (Rutter, Simonoff, \& Silberg, 1993). It should be stated, however, that if twinning is a risk factor for $\mathrm{CD}$, this would most likely lead to reduced estimates of the contribution of genetic factors and inflated estimates of either shared or nonshared environmental factors in its etiology. Thus, the violation of this twin-method assumption is unlikely to be of importance in the present study.

The other major assumption of the twin method that must be considered is that the environmental influences relevant to the development of $\mathrm{CD}$ are not more similar in $\mathrm{MZ}$ than $\mathrm{DZ}$ twin pairs. When this assumption is not met, estimates of genetic infiuences obtained from twin studies may be inflated. Indeed, in the present study, we found that $\mathrm{MZ}$ twins were more likely than $\mathrm{DZ}$ twins to have the same friends as children and that this significantly predicted twin concordance for $C D$. This is consistent with a large literature on the association between peer relationships and $\mathrm{CD}$. The interpretation of this association, however, is somewhat problematic because the direction of causation is unclear. Although associating with delinquent peers may cause a child to engage in delinquent behaviors, there is also evidence in favor of the alternative hypothesis - that children associate with peers who are similar to them (Rowe, 1994). Delinquent children are more likely to associate with delinquent peers. Baker and Daniels (1990; see also Rowe, 1994), comparing $\mathrm{MZ}$ twins, $\mathrm{DZ}$ twins, full siblings, and adopted siblings for similarity of peer group characteristics, showed that more

\footnotetext{
${ }^{3}$ We thank Mike Neale for this idea.
} 
genetically similar siblings had peer groups that were more similar for their participation in delinquent behaviors; this finding has subsequently been replicated by other investigators (see Plomin, 1995). Thus, genetically influenced characteristics, in part, lead children to seek out particular peer groups (Scarr \& McCartney, 1983). Of particular interest is the finding that the delinquency score of one's MZ cotwin predicts an adolescent's peer group affiliation nearly as well as the adolescent's own delinquency score and better than the delinquency score of a DZ cotwin. In other words, genetic factors largely explain the strong correlation between antisocial behavior and delinquent peer group affiliation (Rowe \& Osgood, 1984). Thus, the finding of greater concordance for $\mathrm{CD}$ in twins who shared playmates as children does not necessarily imply that genetic infiuences for $C D$ are overestimated in the present study, because there is evidence to suggest that peer choice is itself a genetically driven behavior.

The frequency of current contact as adults also significantly predicted twin concordance for $\mathrm{CD}$, although the similarity of twins who were in more frequent contact did not differ signifcantly from the similarity of twins in less frequent contact. Here too, the direction of causation of the association is open to debate (Lykken, Bouchard, \& Tellegen, 1990; Rose, Kaprio, Williams, Viken, \& Obremski, 1990). It is quite likely that twins who are more similar as children are more likely to be in frequent contact as adults. However, we cannot exclude the possibility that the frequency of current contact as adults can influence the similarity of adult reports of childhood $C D$, independent of the true childhood similarity. Given the findings in the present study of increased concordance for $C D$ in twin pairs who shared the same friends as children and who were in more frequent contact as adults, future twin studies of $C D$ prospectively assessed in children should include a broader array of environmental risk factors to more fully evaluate the validity of the equal environmental similarity assumption for this disorder.

Another related concern for twin studies of antisocial behaviors is that twins sometimes engage in antisocial acts together (Rowe, 1985) or may influence each other's behaviors more indirectly (Carey, 1992). Carey (1992) demonstrated that when sibling imitation is not accounted for in the statistical modeling of twin data, genetic influences may be overestimated. Unfortunately, we did not ask participants whether antisocial behaviors were jointly committed with a cotwin. However, the expected $M Z-D Z$ difference in prevalence (higher rates of $C D$ in $M Z$ than in $\mathrm{DZ}$ twins) that would be expected if twin imitation were operative was not observed. Nonetheless, this does not rule out the possibility that part of the estimated genetic variation in the present study may reflect twin imitation. Clearly, the role of sibling influences in the development of $C D$ and the impact of sibling imitation on estimates of genetic and environmental variation obtained from twin studies are areas that deserve further study.

\section{Implications}

The results of the present study have important implications for the types of risk factors that are likely to contribute to the liability to develop $C D$. For example, we could not reject the possibility that associating with delinquent peers may increase a child's risk of developing $C D$, although recent longitudinal studies of delinquent or disruptive behaviors in children suggest that the influence of peers is modest once the prior level of delinquent behavior in the child is taken into consideration (Hoza, Molina, Bukowski, \& Sippola, 1995; Tremblay, Masse, Vitaro, \& Dobkin, 1995). The relationship between peer influences and $C D$ most likely reflects both genetic (assortative friendship) and environmental (peer imitation) mechanisms. Extended twin designs that also gather information from the friends of twins may help to better understand this important association.

Another promising area for future research is the identification of traits that mediate the genetic influences on $\mathrm{CD}$. Personality traits such as deceitfuiness (Rowe, 1986), anger or aggression (Krueger et al., 1994; Rowe, 1986), impulsivity (Krueger et al., 1994; Rowe, 1986; Tremblay, Pihl, Vitaro, \& Dobkins 1994; White et al., 1994), and nonconformity (Kreuger et al. 1994) have been associated with childhood antisocial behaviors, and Rowe (1986) demonstrated that the association of some of these traits with delinquent behaviors is, in part, genetically mediated. Goldsmith and Gottesman (1996) suggest several other promising candidate traits that may constitute the genetic diathesis underlying $\mathrm{CD}$ : need for stimulation, activity level, anxiety proneness, and frustration tolerance. These authors also suggest pathways by which genes might influence conduct-disordered behavior. Clearly, the route through which genes influence CD liability is complex.

This study suggests that the association of parent characteristics and parenting behaviors with $C D$ in offspring may be due to genetic rather than shared family environmental mechanisms. If this is true, then modification of parent characteristics may not have the anticipated effect of reducing antisocial behaviors in their children. Future twin-family studies of $C D$ that include specific family environmental risk factors (e.g., Kendler et al., 1996) will be helpful to further understand the causal significance of these putative risk factors in the development of $C D$.

Even if shared environmental influences play only a minor role in the development of $\mathrm{CD}$ in the majority of individuals, this should not lead to therapeutic nihilism (Meehl, 1972, p. 10). The genetic etiology of a disorder does not imply immutability, and there are many examples of genetically influenced traits that have been modified through environmental interventions: Children's smiles are improved with braces, their vision is improved with eyeglasses, their hearing is improved with hearing aids, and their overall health and growth is improved through proper nutrition. Even single-gene disorders are modifiable through environmental interventions: Babies born with phenylketonuria (PKU), galactosemia (see Plomin et al., 1990), and other metabolic disorders are often able to lead normal lives because of effective therapies. Effective treatments were developed only after the etiology of these disorders was known. Understanding the etiology of $C D$, and particularly the direction of causation of the association of $\mathrm{CD}$ with its putative risk factors, will very likely be helpful in the development of effective interventions for this disorder as well.

\section{References}

Amato, P. R., \& Keith, B. (1991). Parental divorce and the well-being of children: A meta-analysis. Psychological Bulletin, 110, 26-46. 
American Psychiatric Association. (1987). Diagnostic and statistical manual of mental disorders (3rd ed., revised). Washington, DC: Author.

Anderson, J. C., Williams, S., McGee, R., \& Siiva, P. A. (1987). DSMIII disorders in preadolescent children: Prevalence in a large sample from the general population. Archives of General Psychiatr; 4, 6976.

Baker, L. A., \& Daniels, D. (1990). Nonshared environmental influences and personality differences in adult twins. Joumal of Personality and Social Psychology, 58, 103-110.

Biles, D. (1983). Crime and imprisonment: A two-decade comparison between England and Wales and Australia. British Joumal of Criminology, 23, 166-172.

Bucholz, K. K., Cadoret, R., Cloninger, C. R., Dinwiddie, S. H., Hesselbrock, V. M., Numberger, J. I, Jr., Reich, I., Schmidt, I., \& Schuckit M. A. (1994a). A new semi-structured psychiatric interview for use in genetic linkage studies: A report on the reliability of the SSAGA. Journal of Studies on Alcohol, 55, 149-158.

Bucholz, K. K., Cadoret, R., Cloninger, C. R., Dinwiddie, S. H., Hesselbrock, V. M., Nurnberger, J. L., Jr., Reich, I., Schmidt, I., \& Schuckit, M. A. (1994b). [A new semi-structured psychiatric interview for use in genetic linkage studies: A report on the reliability of the SSAGA] Unpublished raw data.

Cadoret, R. J., Yates, W. R., Troughton, E., Woodworth, G., \& Stewarth M. (1995). Genetic-environmental interaction in the genesis of aggressivity and conduct disorders. Archives of General Psychiatry, 52, 916-924.

Carey, G. (1992). Twin imitation for antisocial behavior: Implications for genetic and family environment research. Joumal of Abnormal Psychology, 101, 18-25.

Cloninger, C. R., Christiansen, K. O., Reich, I., \& Gottesman, I.I (1978). Implications of sex differences in the prevalences of antisocial personality, alcoholism, and criminality for familial transmission. Archives of General Psychiatry, 35, 941-951.

Cloninger, C. R., \& Gottesman, I. I. (1987). Genetic and environmental factors in antisocial behavior disorders. In S. A. Mednick, T. E. Moffitt, \& S. A. Stack (Eds.), The causes of crime: New biological approaches (pp. 92-109). Cambridge, England: Cambridge University Press.

Cohen, P., Cohen, J., Kasen, S., Velez, C. N., Hartmark, C., Johnson, J., Rojas, M., Brook, J., \& Streaming, E. L. (1993). An epidemiological study of disorders in late childhood and adolescence-I. Age- and gender-specific prevalence. Journal of Child Psychology and Psychiatry, 34, 851-867.

Cottler, L. B., Kessler, R. C., \& Nelson, C. (1995). Antisocial personality disorder in the National Comorbidity Survey. Mamuscript in preparation.

DiLalla, L. F., \& Gottesman, I I. (1989). Heterogeneity of causes for delinquency and criminality. Lifespan perspectives. Development and Psychopathology, 1, 339-349.

Eaves, L. J., Eysenck, H. J., \& Martin, N. G. (1989). Genes, culture and personality: An empirical approach New York: Academic Press.

Eaves, L. J., Silberg, J. L., Meyer, J. M., Maes, H. H., Simonoff, E., Pickles, A., Rutter, M., Neale, M. C., Reynolds, C. A., Erikson, M. T. Heath, A. C., Loeber, R., Truet, K. R., \& Hewith, J. K. (1995). Genetics and developmental psychopathology: 2 . The main effects of genes and environment on behavioral problems in the Virginia Twin Study of Adolescent Behavioral Development. Manuscript submitted for publication.

Edelbrock, C., Rende, R., Plomin, R., \& Thompson, L. A. (1995). A twin study of competence and problem behavior in childhood and early adolescence. Journal of Child Psychology and Psychiatry, 36, $775-785$.
Emery, R. E. (1982). Interparental conflict and the children of discord and divorce. Psychological Bulletin, 92, 310-330.

Eysenck, H. J., Eysenck, S. B. G., \& Barret, P. (1985). A revised version of the Psychoticism Scale. Personality and Individual Differences, 6 , 21-29.

Falconer, D. S. (1965). The inheritance of liability to certain diseases, estimated from the incidence among relatives. Annals of Human $\mathrm{Ge}$ netics, 29, 51-76.

Fergusson, D. M., Horwood, J., \& Lynskey, M. T (1994). Parental separation, adolescent psychopathology, and problem behaviors. Journa of the American Academy of Child and Adolescent Psychiatry; 33, 1122-1131.

Fingerhut, L. A., \& Kleinman, J. C. (1990). International and interstate comparisons of homocide among young males. Joumal of the American Medical Association, 263, 3293-3295.

Fleiss, J. L. (1981). Statistical methods for rates and proportions (2nd ed.). New York Wiley.

Frick, P. J., Lahey, B. B., Loeber, R., Stouthamer-Loeber, M., Christ, M. A., \& Hanson, K. (1992). Familial risk factors to oppositional defiant disorder and conduct disorder. Parental psychopathology and maternal parenting. Joumal of Consulting and Clinical Psychology, $60,49-55$.

Gaw, J. S., Silberg, J. L., Erickson, M. T., \& Hewith, J. K. (1992). Childhood behavior problems: A comparison of twin and non-twin samples. Acta Geneticae Medicae et Gemellologiae, 41, 53-63.

Goldsmith, H. H., \& Gottesman, I. I. (1996). Heritable variability and variable heritability in developmental psychopathology. In M. Lenzenweger \& J. Haugaard (Eds.), Frontiers of developmental psychopathology (pp. 5-43). New York: Oxford University Press.

Goodman, S. H., \& Kohlsdorf, B. (1994). The developmental psychopathology of conduct problems: Gender issues. In D. C. Fowles, P Sutker, \& S. H. Goodman (Eds.), Progress in experimental personality \& psychopathology research 1994 (pp. 121-161). New York Springer

Gottesman, I. I., \& Shields, J. (1967). A polygenic theory of schizophrenia Proceedings of the National Academy of Sciences, 58, 199-205.

Grove, W. M., Eckert, E. D., Heston, L., Bouchard, T. J., Jr., Segal, N., \& Lykken, D. I. (1990). Heritability of substance abuse and antisocial behavior: A study of monozygotic twins reared apart. Biological Psychiatry, 27, 1293-1304.

Heath, A. C., Bucholz, K. K., Slutske, W. S., Madden, P. A. F., Dinwiddie, S. H., Dunne, M. P., Statham, D. B., Whitfield, J. B., Martin, N. G., \& Eaves, L. J. (1994). The assessment of alcoholism in surveys of the general community: What are we measuring? Some insights from the Australian twin panel interview survey. International Review of Psychiatry, 6, 295-307.

Heath, A. C., Cloninger, C. R., \& Martin, N. G. (1994). Testing a model for the genetic structure of personality: A comparison of the personality systems of Cloninger and Eysenck Joumal of Personality and Social Psychology, 66, 762-775.

Heath, A. C., Madden, P. A. F., Bucholz, K. K., Slutske, W. S., Bierut, L. J., \& Martin, N. G. (1996, June). Assessing the effects of cooperation bias and attrition in longitudinal psychiatric genetic research Paper presented at the meeting of the Behavior Genetics Association, Pitusburgh, PA.

Heath, A. C., \& Martin, N. G. (1992). Genetic differences in psychomotor performance decrement after alcohol: A multivariate analysis. Journal of Studies on Alcohol, 53, 262-271.

Heath, A. C., \& Martin, N. G. (1993). Genetic models for the natural history of smoking: Evidence for a genetic influence on smoking persistence. Addictive Behaviors, 18, 19-34.

Heath, A. C., \& Martin, N. G. (1994). Genetic influences on alcohol consumption patterns and problem drinking: Results from the Austra- 
lian NH\&MRC twin panel follow-up survey. Annals of the New York Academy of Science, 708, 72-85.

Heath, A. C., Neale, M. C., Hewitt, J. K., Eaves, L. J., \& Fulker, D. W. (1989). Testing structural equation models for twin data using LISREL. Behavior Genetics, 19, 9-35.

Henry, B., Moffitt, T. E., Caspi, A., Langley, J., \& Silva, P. A. (1994). On the "remembrance of things past": A longitudinal evaluation of the retrospective method. Psychological Assessment, 6, 92-101.

Hindelang, M. J., Hirschi, T., \& Weis, J. G. (1981). Measuring delinquency. Beverly Hills, CA: Sage.

Hinshaw, S. P. (1994). Conduct-disorder in childhood: Concepualization, diagnosis, comorbidity, and risk status for antisocial functioning in adulthood. In D. C. Fowles, P. Sutker, \& S. H. Goodman (Eds.), Progress in experimental personality \& psychopathology research 1994 (pp. 3-44). New York Springer.

Hinshaw, S. P., Lahey, B. B., \& Hart, E. L. (1993). Issues of taxonomy and comorbidity in the development of conduct disorder. Development and Psychopathology, 5, 31-49.

Hirschi, T., Hindelang, M. J., \& Weis, J. G. (1980). The status of selfreport measures. In M. W. Klein \& K. S. Teilmann (Eds.), Handbook of criminal justice evaluation (pp. 473-488). Beverly Hills, CA: Sage.

Hoza, B., Molina, B. S. G., Bukowski, W. M., \& Sippola, L. K. (1995). Peer variables as predictors of later childhood adjustment. Development and Psychopathology, 7, 787-802.

Jardine, R., \& Martin, N. G. (1984). Causes of variation in drinking habits in a large twin sample. Acta Geneticae Medicae et Gemellologicae, 33, 435-450.

Joreskog, K. G., \& Sorbom, D. (1988). PRELIS: A preprocessor for LISREL Mooresville, IN: Scientific Software.

Kazdin, A. E. (1987). Treatment of antisocial behavior in children: Current status and future directions. Psychological Bulletin, 102, 187203.

Kendier, K. S. (1993). Twin studies of psychiatric illness: Current status and future directions. Archives of General Psychiatry, 50, 905-915.

Kendler, K. S., Neale, M. C., Kessler, R. C., Heath, A. C., \& Eaves, L. J. (1992). Childhood parental loss and adult psychopathology in women. Archives of General Psychiatry, 49, 109-116.

Kendler, K. S., Neale, M. C., Kessler, R. C., Heath, A. C., \& Eaves, L. J. (1993). A test of the equal-environment assumption in twin studies of psychiarric illness. Behavior Genetics, 23, 21-27.

Kendler, K. S., Neale, M. C., Prescott, C. A., Kessler, R. C., Heath, A. C., Corey, L. A., \& Eaves, L. J. (1996). Childhood parental loss and alcoholism in women: A causal analysis using a twin-family design. Psychological Medicine, 26, 79-95.

Kessler, R. C., McGonagle, K. A., Zhao, S., Nelson, C. B., Hughes, M., Eshleman, S., Wittchen, H., \& Kendler, K. S. (1994). Lifetime and 12month prevalence of $D S M-I I I-R$ psychiatric disorders in the United States: Results from the National Comorbidity Study. Archives of General Psychiatry, 51, 8-19.

Krueger, R. F., Schmutue, P. S., Caspi, A., Moffitt, T. E., Campbell, K., \& Silva, P. A. (1994). Personality traits are linked to crime among men and women: Evidence from a birth cohort. Journal of Abnormal Psychology, 103, 328-338.

Lahey, B. B., Hartdagen, S. E., Frick, P. J., McBurnett, K., Connor, R., \& Hynd, G. W. (1988). Conduct disorder. Parsing the confounded relation to parental divorce and antisocial personality. Joumal of Abnormal Psychology, 97, 334-337.

Lahey, B. B., Piacentini, J. C., McBurnett, K., Stone, P., Hartdagen, S. E., \& Hynd, G. W. (1988). Psychopathology and antisocial behavior in the parents of children with conduct disorder and hyperactivity. Joumal of the American Academy of Child and Adolescent Psychiatry, 27, 163-170.
Loeber, R., \& Dishion, T. (1983). Early predictors of male delinquency: A review. Psychological Bulletin, 94, 68-99.

Lykken, D. T. (1995). The antisocial personalities. Hillsdale, N]: Erlbaum.

Lykken, D. T., Bouchard, T. J., J., \& Tellegen, A. (1990). Does contact lead to similarity or similarity to contact? Behovior Genetics, 20 , 547-561.

Lyons, M. J. (1996). A twin study of self-reported criminal behaviour In G. R. Bock \& J. A. Goode (Eds.), Genetics of criminal and antisocial behaviour (pp. 61-86). Chichester, England: Wiley.

Lyons, M. J., True, W., Eisen, S., Goldberg, J., Meyer, J., Faraone, S. V., Eaves, L., \& Tsuang, M. T (1995). Differential heritability of adult and juvenile antisocial traits. Archives of General Psychiatry, 52, $906-$ 915.

Lytton, H. (1990). Child and parent effects in boys' conduct disorder: A reinterpretation. Developmental Psychology, 26, 683-697.

Martin, N. G., Oakeshott, J. G., Gibson, J. B., Starmer, G. A., Perl, J., \& Wilks, A. V. (1985). A twin study of psychomotor and physiological responses to an acute dose of alcohol. Behavior Genetics, 15: 30547.

Martin, N. G., Perl, J., Oakeshoth, J. G., Gibson, J. B., Starmer, G. A., \& Wilks, A. V. (1985). A twin study of ethanol metabolism. Behavior Genetics, 15, 93-109.

McGue, M., \& Lykken, D. T. (1992). Genetic influence on risk of divorce. Psychological Science, 3, 368-373.

Meehl, P.E. (1972). Specific genetic etiology, psychodynamics, and therapeutic nihilism. Intemational Joumal of Mental Health, 1, 1027.

Mukherjee, S. (1996). Measuring crime. In K. M. Hazlehurst (Ed.), Crime and justice: An Australian textbook in criminology (pp. 6189). Sydney, Australia: LBC Information Services.

Neale, M. C. (1995). Mx: Statistical modeling (3rd ed.). (Available from M. C. Neale, Box 710 MCV, Richmond, VA 23298)

Neale, M. C., \& Cardon, L. R. (1992). Methodology for genetic studies of twins and families. Dordrecht, The Netherlands: Kluwer Academic.

Neale, M. C., Eaves, L. J., \& Kendlex, K. S. (1994). The power of the classical twin study to resolve variation in threshold traits. Behavior Genetics, 24, 239-258.

Nichols, P. L. (1984). Familial mental retardation. Behavior Genetics, 14, $161-170$.

Olsson, U. (1979). Maximum likelihood estimation of the polychoric correlation coefficient. Psychometrika, 44, 443-460.

Patterson, G. R., DeBaryshe, B. D., \& Ramsey, E. (1989). A developmental perspective on antisocial behavior. American Psychologist, 44, 329-335.

Pearson, J. L., Ialongo, N. S., Hunter, A. G., \& Kellam, S. G. (1994). Family structure and aggressive behavior in a population of urban elementary school children. Journal of the American Academy of Child and Adolescent Psychiatry, 33, 540-548.

Plomin, R. (1995). Genetics and children's experiences in the family. Journal of Child Psychology and Psychiatry, 36, 33-68.

Plomin, R., DeFries, J. C., \& McClearn, G. E. (1990). Behavioral gene1ics: A primer (2nd ed.). New York: W. H. Freeman.

Raine, A. (1993). The psychopathology of crime: Criminal behavior as a clinical disorder. San Diego, CA: Academic Press.

Reich, T., Cloninger, C. R., \& Guze, S. B. (1975). The multifactorial model of disease transmission: I. Description of the model and its use in psychiatry. British Journal of Psychiatry, 127, 1-10.

Reich, T., James, J. W., \& Morris, C. A. (1972). The use of multiple thresholds in determining the mode of transmission of semi-continuous traits. Annals of Human Genetics, 36, 163-184.

Robins, L. N. (1978a). Aetiological implications in studies of childhood histories relating to antisocial personality. In R. D. Hare \& D. Schal- 
ling (Eds.), Psychopathic behaviour: Approaches to research (pp. 255-271). Chichester, England: Wiley.

Robins, L. N. (1978b). Surdy childhood predictors of adult antisocial behaviour: Replications from longiudinal studies. Psychological Medicine, 8, 611-622.

Robins, L. N. (1991). Conduct disorder. Journal of Child Psychology and Psychiatry, 32, 193-212.

Robins, L. N., \& McEvoy, L. (1990). Conduct problems as predictors of substance abuse. In L. N. Robins \& M. Rutter (Eds.), Straight and devious pathways from childhood to adulthood (pp. 182-204). New York: Cambridge University Press.

Robins, L. N., \& Price, R. K. (1991). Adult disorders predicted by childhood conduct problems: Results from the NIMH Epidemiologic Catchment Area Project. Psychiatry, 54, 116-132.

Robins, L. N., \& Regier, D. A. (1991). Psychiatric disorders in America: The Epidemiologic Catchment Area Study. New York: Free Press.

Robins, L. N., Tipp, J., \& Przybeck, T. (1991). Antisocial personality. In L. N. Robins \& D. A. Regier (Eds.), Psychiatric disorders in America: The Epidemiologic Catchment Area Study (pp. 258-290). New York: Free Press.

Rose, R. J., Kaprio, J., Williams, C. J., Viken, R., \& Obremski, K. (1990). Social contact and sibling similarity: Facts, issues, and red herrings. Behavior Genetics, 20, 763-778.

Rowe, D. C. (1983). Biometrical genetic models of self-reported delinquent behavior: A twin study. Behavior Genetics, 13, 473-489.

Rowe, D. C. (1985). Sibling interaction and self-reported delinquent behavior: A study of 265 twin pairs. Criminology, 23, 223-240.

Rowe, D. C. (1986). Genetic and environmental components of antisocial behavior. A study of 265 twin pairs. Criminology, 24, 513-532.

Rowe, D. C. (1994). The limits of family influence: Genes, experience, and behavior. New York: Guilford Press.

Rowe, D. C., \& Osgood, D. W. (1984). Heredity and sociological theories of delinquency: A reconsideration. American Sociological Review, 49, 526-540.

Rowe, D. C., Rodgers, J. L., \& Meseck-Bushey, S. (1992). Sibling delinquency and the family environment: Shared and unshared influences. Child Development, 63, 59-67.

Rutter, M. (1995). Relationships between mental disorders in childhood and adulthood. Acta Psychiatrica Scandinavica, 91, 73-85.

Rutter, M., \& Giller, H. (1983). Juvenile delinquency: Trends and perspectives. Harmondsworth, England: Penguin.

Rutter, M., Macdonald, H., Le Couteur, A., Harrington, R., Bolton, P., \& Bailey, A. (1990). Genetic factors in child psychiatric disorders-II. Empirical findings. Journal of Child Psychology and Psychiatry, 31, 39-83.

Rutter, M., \& Redshaw, J. (1991). Annotation: Growing up as a twin: Twin-singleton differences in psychological development. Journal of Child Psychology and Psychiatry, 32, 885-895.

Rutter, M., Simonoff, E., \& Silberg, J. (1993). How informative are twin studies of child psychopathology? In T. J. Bouchard, Jr., \& P. Propping (Eds.), Twins as a tool of behavioral genetics (pp. 179194). Chichester, England: Wiley.
Scarr, S., \& McCartney, K. (1983). How people make their own environments: A theory of genotype $\rightarrow$ environment effects. Child Development, 54, 424-435.

Silberg, J. L., Erickson, M. T., Meyer, J. M., Eaves, L. J., Rutter, M. L., \& Hewitt, J. K. (1994). The application of structural equation modeling to maternal ratings of twins' behavioral and emotional problems. Journal of Consulting and Clinical Psychology, 62, 510-521.

Simonoff, E. (1992). A comparison of twins and singletons with child psychiatric disorders: An item sheet study. Joumal of Child Psychology and Psychiatry, 33, 1319-1332.

Spitznagel, E. L., \& Helzer, J. E. (1985). A proposed solution to the base rate problem in the kappa statistic. Archives of General Psychiatry, 42, $725-728$.

Stevenson, J., \& Graham, P. (1988). Behavioral deviance in 13-year old twins: An item analysis. Joumal of the American Academy of Child and Adolescent Psychiatry, 27, 791-797.

Szarmari, P., Boyle, M. H., \& Offord, D. R. (1993). Familial aggregation of emotional and behavioral problems of childhood in the general population. American Joumal of Psychiatry, 150, 1398-1403.

Thorpe, K. Golding, J., MacGillivray, I., \& Greenwood, R. (1991). Comparison of prevalence of depression in mothers of twins and mothers of singletons. British Medical Journal, 302, 875-878.

Tremblay, R. E., Masse, L. C., Vitaro, F., \& Dobkin, P. L. (1995). The impact of friends' delinquent behavior on early onset of delinquency: Longitudinal data from 6 to 13 years of age. Development and Psychopathology, 7, 649-667.

Tremblay, R. E., Pihl, R. O., Vitaro, F., \& Dobkin, P. (1994). Predicting early onset of male antisocial behavior from preschool behavior. Archives of General Psychiatry, 51, 732-739.

Twito, T. J., \& Stewart, M. A. (1982). A half-sibling study of aggressive conduct disorder. Neuropsychobiology, 8, 144-150.

van den Oord, E. J. C. G., Boomsma, D. I., \& Verhulst, F. C. (1994). A study of problem behaviors in 10- to 15 -year-old biologically related and unrelated international adoptees. Behavior Genetics, 24, 193205.

van den Oord, E. J.C. G., Koot, H. M., Boomsma, D. I., Verhulst, F. C., \& Orlebeke, J.F. (1995). A twin-singleton comparison of problem behaviour in 2-3-year-olds. Journal of Child Psychology and Psychiatry, 36, 449-458.

Waldman, I. D., Pickens, R. W., \& Svikis, D. S. (1989). Sex differences in genetic and environmental components of childhood conduct problems. Behavior Genetics, 19, 779-780.

Wheeler, T. (1989). Australia: A travel survival kit. Victoria, Australia: Lonely Planet Publications.

White, J. L., Moffitt, T. E., Caspi, A., Jeglum Bartusch, D., Needles, D. J., \& Stouthamer-Loeber, M. (1994). Measuring impulsivity and examining its relationship to delinquency. Journal of Abnormal Psychology, 103, 192-205.

Zoccolillo, M. (1993). Gender and the development of conduct disorder. Development and Psychopathology, 5, 65-78.

Received November 17, 1995 Revision received July 2, 1996 Accepted July 2, 1996 — 